OPEN ACCESS

Edited by:

Di Jin,

Woods Hole Oceanographic Institution, United States

Reviewed by:

Christian T. K.-H. Stadtlander, Independent Researcher, St. Paul,

MN, United States

Jennifer Leigh Bailey,

Norwegian University of Science and Technology, Norway

*Correspondence:

Laura Weiand

Laura.Weiand@iass-potsdam.de

tThese authors share senior authorship

Specialty section

This article was submitted to Marine Affairs and Policy,

a section of the journal

Frontiers in Marine Science

Received: 23 December 2020

Accepted: 17 March 2021

Published: 04 May 2021

Citation:

Weiand L, Unger S, Rochette J, Müller A and Neumann B (2021)

Advancing Ocean Governance in Marine Regions Through Stakeholder Dialogue Processes. Front. Mar. Sci. 8:645576. doi: 10.3389/fmars.2021.645576

\section{Advancing Ocean Governance in Marine Regions Through Stakeholder Dialogue Processes}

\author{
Laura Weiand ${ }^{1 *}$, Sebastian Unger ${ }^{1,2+}$, Julien Rochette ${ }^{3}$, Alexander Müller ${ }^{2}$ and \\ Barbara Neumann ${ }^{1 \dagger}$
}

${ }^{1}$ Institute for Advanced Sustainability Studies, Potsdam, Germany, ${ }^{2}$ TMG-Think Tank for Sustainability, Berlin, Germany, ${ }^{3}$ Institute for Sustainable Development and International Relations, Paris, France

The poor state of the ocean and the transboundary nature of the marine environment require bold action by States coordinated across sectors and territorial boundaries in order to deal with the manifold challenges the ocean is facing-and with it humankind. Cooperation and coordination among States and stakeholders in marine regions have proven to be important levers for policy implementation and to strengthen ocean governance, yet remain challenging. Transparent and engaging stakeholder dialogue processes have the potential to provide guidance for the necessary transformation toward ocean sustainability and support the attainment of Sustainable Development Goal (SDG) for the ocean, SDG 14 and other interlinked ocean-related targets. The aim of this study is to review the challenges and opportunities of current collaborative efforts, namely multi-stakeholder dialogue and exchange processes, within and between marine regions to accelerate transformative action, contributing to these global goals. This paper builds on knowledge co-production and collaborative governance literature, and reviews experiences by stakeholders with ocean-related science-policy interfaces in an effort to strengthen regional ocean governance. As an exemplary case of such interfaces, this study assesses the Marine Regions Forum, a newly established inclusive dialogue and exchange platform for diverse actors from marine regions that aims to provide an informal space for joint learning and support regional action and international governance processes alike. Employing latent content analysis of interviews with experts, critical common barriers that hamper current collaborative efforts amongst stakeholders in marine regions are identified, such as fragmented governance frameworks, power and resource imbalances, and lack of meaningful stakeholder engagement. Pathways to address these challenges, such as through common goal orientation, contextualisation, inclusivity, trust building and meaningful continuous interactions are also identified. This paper concludes by discussing the value added of transparent and inclusive collaborative processes in the transformation of ocean governance toward achieving sustainability.

Keywords: marine regions, stakeholders, participation, science-policy, knowledge exchange, collaborative processes, ocean governance, sustainability 


\section{INTRODUCTION}

The current ocean management and governance frameworks are often referred to as fragmented and critiqued for not effectively addressing threats to the ocean (Chung, 2010; Rochette et al., 2015; Heinrich Böll Foundation, 2017; Watson-Wright and Luis Valdés, 2019) as the frameworks are largely built on the matrix of traditional sector-based or issue-based mechanisms. This approach is seen to hinder concerted action toward achieving sustainability goals, specifically the Sustainable Development Goal (SDG) 14 "Life below water" of the United Nations' 2030 Agenda for Sustainable Development (United Nations, 2015). Due to the interconnected nature of the 2030 Agenda and SDGs, a fundamental prerequisite to the successful implementation of the SDGs includes ensuring that multiple actors work together across scales, times, and diverse contexts (Bowen et al., 2017; Schmidt et al., 2017; Stafford-Smith et al., 2017). This also applies to the ocean, and given the specificities of the marine environment including its transboundary nature, responses need to be collaborative across sectors, stakeholder groups, and territorial boundaries in order to be truly effective.

A well-recognised enabler of transformative change toward sustainability is the evolving and promising cluster of collaborative approaches, namely participatory and transdisciplinary practices (Mauser et al., 2013; Norström et al., 2020; Schmidt et al., 2020). As explained in Mauser et al. (2013), knowledge integration and transdisciplinarity is an iterative process that requires self-reflexivity and consists of codesign, co-production, and co-dissemination. Integrated marine governance through stakeholder engagement across sectors and levels is increasingly being committed to in ocean sustainability practices and marine governance framework (Van Tatenhove, 2011), yet they are far from being widely implemented or assessed. Further, practices of co-production are highly variable (Bremer and Meisch, 2017). Although this provides space for flexibility in approaches, it limits the ability to learn from them and improve their effectiveness (Norström et al., 2020) to ultimately foster the transformative change that is needed.

There is a rich body of literature on the co-production of knowledge in the science-policy system (Dale and Armitage, 2011; Cvitanovic et al., 2014, 2015; West et al., 2019; Norström et al., 2020) as well as on collaborative governance theories and practices (Booher, 2004; Ansell and Gash, 2007; Voorberg et al., 2015) upon which this paper builds. In the context of governance, Dale and Armitage (2011) define knowledge co-production as "the collaborative process of bringing a plurality of knowledge sources and types together to address a defined problem and build an integrated or systems-oriented understanding of that problem." Drawing on this literature, this paper refers to collaborative processes within the context of multi-stakeholder processes and knowledge co-production in formal and informal settings of regional ocean governance, either within or between marine regions.

Limited research has been conducted on evaluating collaborative efforts and processes specific to ocean governance (Berkowitz et al., 2020). Efforts have been made to for example analyse the financial benefits of multi-national collaborations for marine conservation (Mazor et al., 2013) and to assess the meta-organisations to identify conditions for successful cooperation in ocean processes (Berkowitz et al., 2020). Yet the majority of the literature focuses on tool-specific stakeholder engagement, for example, marine spatial planning (Ritchie and Lewis, 2003; Gopnik et al., 2012) or integrated coastal zone management (Le Tissier and Hills, 2010). The scope and nature of participatory engagement within ocean-related processes was long described as "a neglected topic" (Ritchie and Ellis, 2010). With this perspective, the current paper aims to contribute to the literature and bridge the gap by assessing collaborative efforts and strategies, specifically multi-stakeholder and cross-sectoral engagement for joint-learning and exchange in marine regions.

There is a dire need to enhance genuine collaborations which are multi-stakeholder and cross-sectoral within and between marine regions. However, most mechanisms that could deliver such opportunities are bound to policy or governance mechanisms, potentially discouraging open exchange and not necessarily fostering innovation. In response to this, Germany announced in 2017 at the UN Ocean Conference in New York, and then together with the European Union (EU) at the 2017 Our Ocean Conference in Malta, that a platform would be setup by 2020 to bring together diverse range of stakeholders to strengthen cooperation and to support the development of new approaches for integrated ocean governance at the regional level (United Nations, 2017). The Marine Regions Forum (henceforth, also the Forum) emerged from this commitment and was setup as an informal, transdisciplinary, and participatory space at the science-policy interface for marine regions. The Forum aimed to investigate policy, management, and governance innovations, in order to facilitate collaborative work that could trigger transformative change for current ocean sustainability challenges.

The first international conference of the Marine Regions Forum was held in Berlin, Germany, from 30 September until 2 October 2019 as an in-person event and brought together over 200 international participants from multiple sectors and stakeholders groups and different marine regions (see Institute for Advanced Sustainability Studies et al., 2020; Neumann et al., 2021). It took the form of a dialogue-oriented conference that included a mixture of interactive workshops and plenary discussions and was complemented by a side programme to foster a creative space for open, informal and productive exchange. From concept development over planning and hosting of the Forum, a co-creative, transdisciplinary, and participatory approach was employed in which independent research institutes worked together with experts from policy-making and civilsociety (see Neumann et al., 2021). The Forum strived to support transformations toward integrated ocean governance for marine regions by advancing multi-stakeholder dialogue, facilitating exchanges of good-practices and cooperation between marine regions through joint-learning processes. The informal nature of the Forum provided a space outside of formal governance arrangements where stakeholders engage in discussion on equal footing as individual experts. It functions as a newly established inclusive dialogue and exchange platform, bringing actors together across multiple stakeholder groups, sectors, and marine regions in a genuine effort to enable the transformative 
change for the sustainable use and conservation of marine environments. The Forum aims to facilitate action at the regional level, thereby supporting the implementation of the 2030 Agenda for Sustainable Development, in particular SDG 14, and build a bridge to a post-2020 pathway for ocean health.

Building on collaborative governance theory, specifically Ansell and Gash (2007) and knowledge co-production principles (Norström et al., 2020), this paper seeks to identify the challenges of implementing collaborative processes and strategies in marine regions and underpin practical pathways to overcoming these challenges. In assessing the Marine Regions Forum 2019 as a case study, this paper demonstrates how collaboration can be fostered within and between marine regions and examines the value added and transformative potential of such practices for formal ocean sustainability processes, including at the global scale. Building on a theoretical framework developed from the relevant scholarly literature, specifically on Ansell and Gash (2007) who provide a model to identify challenges and limitations of collaborative strategies, empirical insights are gained through latent content analysis of interviews conducted with selected experts and participants of the Marine Regions Forum 2019.

Providing a universal prescriptive definition of the term "marine regions" is challenging within the scope of this paper, given that the spatial and institutional boundaries of marine regions can overlap, are variable, region-specific and also complex from a political, legal and ecological perspective. Literature has delineated marine regions based on various different characteristics, including oceanography, Marine Ecoregions, Large Marine Ecosystems boundaries (Morgan, 1991; Spalding et al., 2007), or hierarchical clustering of regional arrangements (Mahon and Fanning, 2019). Mahon and Fanning (2019) defined 20 ocean regions based on the UN Environment's Regional Seas regions and other regional institutional arrangements, corresponding to the coasts and semi-enclosed seas of the continents. Although it seems reasonable to define marine regions, this paper acknowledges the diversity of geopolitical conditions of marine regions and that there is no uniform definition and globally applicable way to set boundaries. Further, dialogue and exchange processes can take place between the global and regional level (i.e., in an effort to harmonise and implement global targets), within and between marine regions (i.e., facilitating action from the global to national level), and between the regional and national level (i.e., to support on-the-ground implementation). The scope of this paper concentrates on the regional and interregional level and further links this to global processes.

\section{MATERIALS AND METHODS}

The analytical framework that guides this paper builds on knowledge co-production principles (e.g., Norström et al., 2020) and collaborative governance models, in particular Ansell and Gash (2007) who provide a contingency theory of the critical variables found to be important in collaborative governance processes. These included "prior history of conflict or cooperation, incentives for stakeholders to participate, power and resources imbalances, leadership, and institutional design" (Ansell and Gash, 2007). Based on these variables, semistructured, in-depth interviews were conducted to explore multistakeholder dialogue and collaborative processes in and across marine regions, how they can foster transformative action to support SDG 14 implementation, as well as understand how informal dialogue platforms can facilitate transformation toward ocean sustainability.

To provide an in-depth case study, the Marine Regions Forum, as an example for a transdisciplinary and collaborative initiative, is reflected upon and utilised to assess the potential and limitations of genuine efforts to enable inclusive dialogue and exchange within and between marine regions. The Forum sought to provide new and innovative ways for inclusive dialogue and exchange on various issues relating to ocean governance with a focus at the regional level. At its first international conference in autumn 2019, it brought together a diversity of actors from different sectors and marine regions to engage in informal joint learning and collaboration, in an effort to create new knowledge, bridge gaps between efforts and strengthen regional governance through new partnerships or approaches. Participants were individually selected and invited by the Forum organisers in order to facilitate a balanced representation of stakeholder groups and regions. The majority of the participants at the Marine Regions Forum 2019 were from research (37\%), followed by intergovernmental organisations (24\%), government (19\%), and NGOs (13\%). 1\% of the participants were from industry and $4 \%$ were categorised as artists. The expertise of half the participants (50\%) was at the global level, while the other half of the participants mainly specialised on particular marine regions, for example, the Western Indian Ocean, South East Atlantic, Pacific, or Arctic. With regards to gender representation, $55 \%$ were male and $45 \%$ were female. Under the leadership of three research institutions who provided core conceptualisation and scientific perspectives, the Forum was co-produced by an interdisciplinary team of ocean researchers and experts, together with a steering group who provided governmental and policy perspectives, and an advisory board of esteemed experts for global and regional level stakeholder and science perspectives (see Neumann et al., 2021). The ambition of the Forum was to position itself outside of formal governance processes and enable common understandings of challenges and opportunities faced by marine regions, and ultimately, to facilitate collective responses. The purpose of the Forum was to support and complement existing efforts by organising an innovative forum for exchange and cooperation.

Expert interviews were conducted during June 2020, 8 months after the Marine Regions Forum 2019 took place. To assess if the interview questions were comprehendible, unambiguous, and informative to the objectives of the study, a preliminary test-interview was conducted internally with a research group member, the data of which was excluded from this studies analysis. Due to the geographical distribution of the interviewees and restrictions due to the COVID-19 pandemic, interviews were held online through a video communication portal. Interviews ranged in length from approximately 40 to $60 \mathrm{~min}$ and were held in English. The timing of the interviews was purposively 
conducted several months after the Marine Regions Forum 2019 took place, in order to provide the ability to study longer-term outcomes of the first Forum. However, it should be acknowledged that such an extended time period can also lead to potential recall-biases by interviewees.

Interviewees were selected from the pool of attendees present at the Marine Regions Forum 2019 through "purposive" sampling (Ritchie and Lewis, 2003). To ensure data saturation - the point at which no new information or themes are observed in the data (Guest et al., 2006), 12 interview participants were identified and selected, of which 11 participated in this study. The interviewee selection process was based on a predetermined key criterion which targeted participants deeply involved with the topic while ensuring a diverse sample to capture the perspectives of different stakeholders. The key criteria considered the following characteristics of potential interviewees (relevance is indicated by the listed order): (i) attendance of the Marine Regions Forum 2019 which serves as a case study for this paper; (ii) experience with multi-stakeholder knowledge exchange frameworks in the context of SDG14 and ocean governance; (iii) representative of different stakeholder groups with practitioner focus (governmental organisations, intergovernmental organisations, non-governmental organisations, and research and academia); (iv) regional diversity; and (v) gender diversity. The regional representation of the interviewees included the following: Western Indian Ocean $(n=2)$, Pacific $(n=3)$, Caribbean $(n=1)$, NW Atlantic $(n=1)$, S Atlantic $(n=1)$, and the global level $(n=3)$. Interviewees were fairly evenly distributed across intergovernmental organisations $(n=4)$, non-governmental organisations $(n=3)$, and research and academia $(n=4)$. Among the 11 study participants, there was a 5:6 female to male gender ratio. Although conducting interviews with representatives from industry would have provided another stakeholder group perspective, it was not possible given their overall low representation at the Marine Regions Forum 2019.

Potential interviewees from the pre-selected pool $(n=12)$ were invited via email to participate in the study. An information sheet was provided to the participants in advance of the interview explaining the purpose of the interview and demands on the interviewee, and to collect informed consent. The informants were assured that confidentiality would be maintained throughout to allow for an open and honest dialogue. Furthermore, an interview guide (see Supplementary Information 1) was prepared to provide a structural frame for the interviews. Interview questions were grouped into two main themes: firstly, on the challenges and opportunities of current multi-stakeholder cross-sectoral exchange processes in and amongst marine regions, based on the analytical framework of this study which was derived from relevant literature (Ansell and Gash, 2007; Norström et al., 2020); secondly, on the interviewees perception of the Marine Regions Forum 2019 including lessons learned at an individual and collective level, and its transformative potential as an informal and inclusive collaborative processes to foster the transformation of ocean governance toward sustainability.
The interviews were recorded as audio files through the video communication portal. The recorded interviews were transcribed verbatim and subsequently investigated through latent content analysis to search for common themes upon which the data was categorised and codes were applied (Hay, 2010). The qualitative data was analysed with the coding software MAXQDA 2020 (VERBI Software, 2019). A hybrid approach of inductive and deductive coding techniques was conducted (see Fereday and Eimear, 2006) as an iterative and reflexive process. Inductive coding was implemented to identify variables that may only manifest in this context or dataset (data-driven) and deductive coding was used to build on the analytical framework of the study derived from literature (theory-driven). After initial coding of the interview data, the codes were subsequently refined and categorised upon which a codebook was developed (DeCuir-Gunby et al., 2011; see also Supplementary Table 1). The overall coding categorisation was based on the two main interview themes described above, under which sub-categories for individual codes were established to provide more detail and further operationalisation of the codes.

\section{RESULTS}

The results are reported according to the key themes which emerged through the in-depth semi-structured interviews and general structure of the interview guide. The first section describes current multi-stakeholder processes in marine regions, including the challenges and principles to overcome such barriers. The second section relates directly to the Marine Regions Forum case study by exploring the participants' perceptions of the 2019 event as a multi-stakeholder crosssectoral dialogue platform. Key interview themes are presented below in a consecutive order; however, it must be recognised that collaborative processes are themselves iterative and non-linear.

It should be acknowledged that in general, collaborative processes are highly diverse and context-specific, especially across marine regions which challenge the ability to apply a universal approach to all collaborative efforts. However, across the board, there were overlaps regarding the interviewee's perceptions on the challenges and potential pathways to address these in order to advance multi-stakeholder exchange processes in marine regions.

\section{Critical Starting Conditions Commonly Hampering Collaborative Processes in Marine Regions}

The starting conditions present at the onset of new collaborative processes are critical as they can facilitate or discourage cooperation and coordination between stakeholders (Ansell and Gash, 2007). Interviewees stated that in ocean sustainability processes, common starting scenarios which discourage cooperation are the traditional sector-based approaches as well as the complex socio-economic structures amongst and within marine regions that usually result in uneven playing field (see Figure 1, left box). This has created governance landscapes that are fragmented and multi-layered. Spaces to encourage or facilitate multi-stakeholder cross-sectoral dialogue 


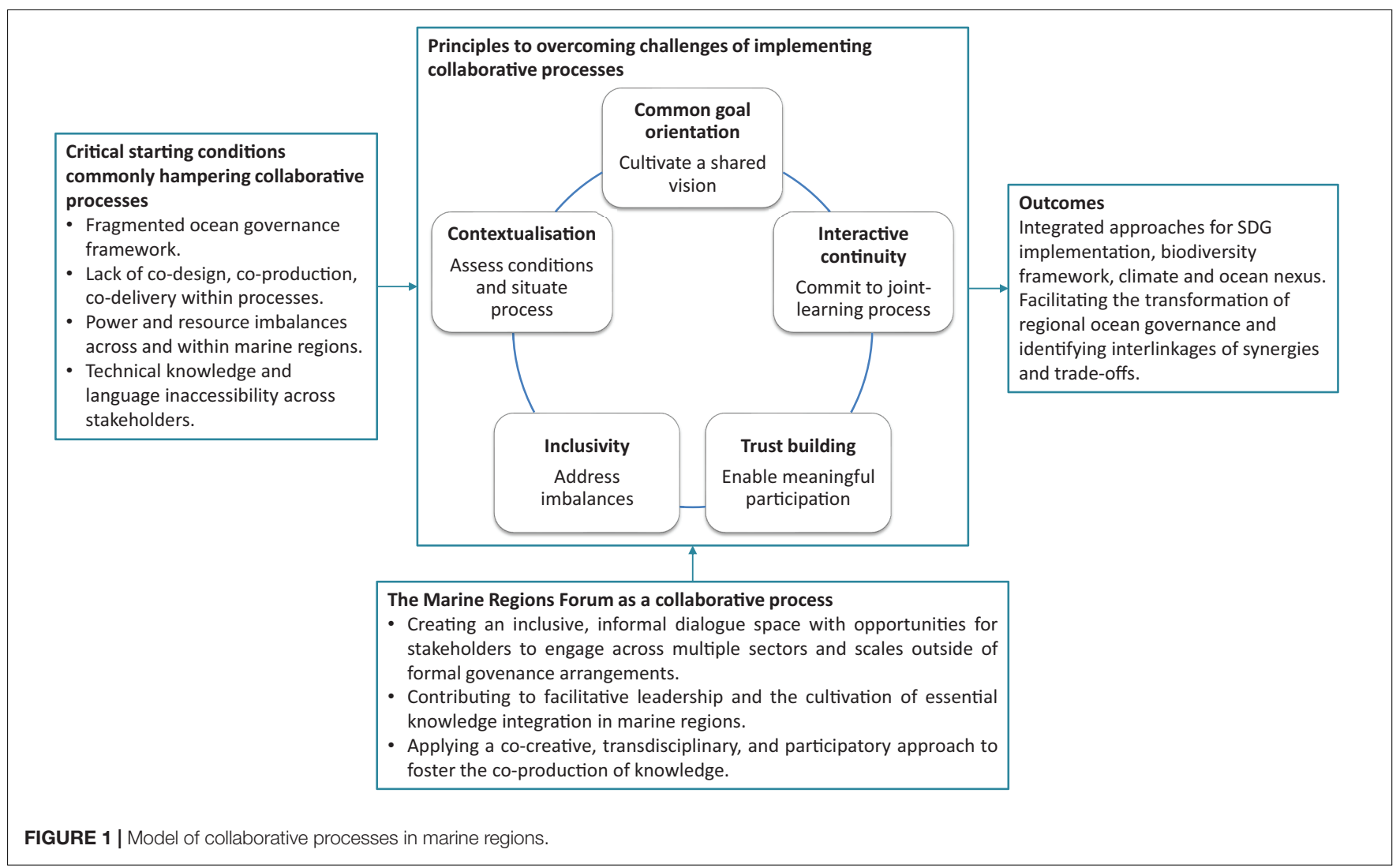

processes are considered rare in regional ocean governance, especially such where the private sector is present. However, according to the interviewees, efforts are increasing and meetings such as those held by regional instruments and conventions (Wright et al., 2017) are being opened to non-governmental organisations, civil society, and intergovernmental bodies. When spaces for engagement do exist, there is frequently a lack of understanding, preparedness, and training for stakeholders about what collaborative engagement is and how to meaningfully engage in such processes.

Interviewees emphasised that building trust and longterm commitments between stakeholders is key for successful collaborative efforts, but these are time-consuming processes which require interactive continuity of cooperation between stakeholders. Even if cooperation has been established, barriers to interactive continuity and trust can persist, especially under variable conditions. For instance, key stakeholders engaged in a collaboration may change positions, funding periods come to a close, or the initial environmental or socio-economic state evolves, all of which make building and continuing long-term commitments challenging.

Power imbalances among stakeholders at the governmental and non-governmental level are also a challenge for collaborative efforts within marine regions. In some contexts, regional instruments are considered weak within national systems, while other bodies, such as funding donors, can be overpowering by imposing stringent conditions or processes that potentially instrumentalise partners. Such asymmetries vary across the regional and national level as some stakeholders lack capacity, status, or resources to participate on equal footing more than other stakeholders, resulting in some collaborative processes (such as negotiations or cooperations) in marine regions to be skewed toward the stakeholders with more power and resources. This is further compounded when certain regions have larger and more diffuse institutional structures which put them at a disadvantage compared to regions with more cohesive and stronger economic bodies. However, one interviewee stated that representing a region with fewer resources and therefore fewer specialists requires the representative to attend meetings or negotiations across a variety of topics and sectors, providing them with a more comprehensive understanding compared to specialists that remain in their thematic silo as there are enough human resources to cover each discipline.

Interviewees also noted that there is often a lack of codesign, co-production, and co-delivery from the onset of the collaborative process - from problem identification, design of the response, to implementation of appropriate measures. When such processes do not properly involve the appropriate key stakeholders from the beginning, such as those most affected or vulnerable (e.g., local communities, minorities, or poor communities) or sectors with considerable power leverage (e.g., private industry), it can result in token involvement and unfavourable conditions, further deepening power imbalances. Furthermore, interviewees stated that this results in under or misrepresentation of key stakeholders especially if they lack 
resources or institutional infrastructure to engage in or attend dialogue processes where collaborations and decision-making takes place. Histories of token engagement where stakeholder perspectives are only partially acknowledged, or not at all, further manifest deep-rooted challenges of trust. Given the vastness of some marine regions, simply getting the right people in the right place is a challenge for underrepresented and under-resourced stakeholders groups.

Interviewees were emphatic that the acquisition of technical knowledge about the environment was considered a central contribution to dialogue processes, particularly for establishing common targets, criteria and standards (e.g., combatting marine pollution in a marine region). A common challenge is the inaccessibility of the technical language used during international multi-stakeholder collaborative processes which may undermine meaningful engagement. Some stakeholders may not have the expertise or resources to engage in technical or political discussions, such as those commonly led by formal political delegations in advance of negotiations, and their perspectives are consequently not accounted for. Interviewees also stated that capacity building especially regarding technical knowledge is distributed unevenly among stakeholders and nations.

Complex socio-economic and political structures within and across marine regions make it challenging to decide which targets to prioritise, especially in establishing targets that all regional instruments and national governments can realistically commit to. This is especially the case when political dynamics and manoeuvrability are stringent or when resources and capacity limit their ability to implement measures. This is further compounded by uncompromising political positioning; however, interviewees stated that multi-stakeholder dialogue and cooperation can provide a better understanding of what a marine region can deliver collectively, by taking into account the heterogeneous socio-economic, cultural, political and geographical characteristics, and implementing more realistic policy instruments through meaningful incremental progress.

\section{Principles to Overcoming Challenges of Implementing Collaborative Processes in Marine Regions}

Key aspects raised during the interviews to overcoming common challenges of multi-stakeholder dialogue processes in marine regions identified above, include: contextualisation, common goal orientation, inclusivity, trust building, and interactive continuity. These five broad variables (see Figure 1, middle upper box) show overlap, and are not independent of each other but rather interlinked. Given the highly context specific nature and non-linear, complex character of collaborations, these variables are regarded as a generalisation and simplification of the process. However, the following section explores each variable in more detail.

\section{Contextualisation}

Interviewees noted that collaborative processes should be situated according to associated confines and opportunities of the highly contextual social, economic, and ecological characteristics of a marine region. Contextualisation can occur at the local, regional, and global level, with the understanding that it pertains to a set of defined issues (Norström et al., 2020). Positioning a cross-sectoral multi-stakeholder dialogue process involves understanding how challenges have occurred or persisted, and how having multistakeholder cross-sectoral dialogue is likely to influence efforts and offer pathways to address challenges. Collaborative efforts should from the onset raise appropriate questions, for example: what are the critical current conditions that may be inhibiting collaboration and what are the entry points or policy windows of opportunity to overcome such challenges? Who are the key players and affected stakeholders and where do power imbalances occur? How effective are current collaborative processes in utilising knowledge within rather than for processes? Ambitious thinking is needed to identify ways of bridging collaboration gaps and to develop formal and informal collaborative structures for policy integration.

Multi-stakeholder engagement processes are considered uncommon in marine regions, also by the interviewees. A fairly straightforward approach to start addressing challenges pertaining to collaborative efforts is by ensuring mechanisms or platforms that facilitate multi-stakeholder dialogue across sectors exist and are valued at the appropriate levels, from national to regional to global level. One interviewee provided an example where national Caribbean governments have been attempting to establish multi-sectoral committees, such as for coastal zone management, with the intention of collaborating on key technical and policy aspects. However, the level of engagement of civil society, NGO's and private sector frequently lacks, also in the example provided. Spaces to have high-quality multi-stakeholder and cross-sectoral exchanges must be available across all marine regions. Such spaces should provide vulnerable and invested stakeholders with opportunities to actively engage, understand, and contribute to emerging decision processes on technical knowledge or policy windows, especially if these can have longlasting implications for the marine region itself. One interviewee stated that regional mechanisms should enable inclusive, crosssectoral decision spaces to discuss transboundary issues, such as marine pollution, offshore exploration or biodiversity loss at a technical and policy relevant level. At the regional level, such spaces could be facilitated by existing regional bodies such as the Regional Seas programmes, most of which are supported or coordinated by the United Nations Environment Programme (UNEP), or the Large Marine Ecosystem mechanisms which is supported by the Global Environment Facility (GEF). However, it should be acknowledged that regional ocean governance mechanisms themselves raise concerns of coordination and efficiency (Billé et al., 2017). Interviewees stated that challenges of socio-economic disparities, power relationships, and resource imbalances need to be addressed from the on-set of a collaborative effort to create more even footing.

\section{Common Goal Orientation}

Pathways to address ocean sustainability challenges require collective understanding, meaningful goal-orientated thinking, and integrated approaches to cooperation. Interviewees acknowledge that high-quality collaborative efforts orient around 
a common mind-frame and vision, mutual understanding and interests, and set of strategic objectives which take different perspectives of key players into account that are also acknowledged by all other stakeholders involved. This is especially important for a long-term trusting and working relationship, and to find the necessary compromises among stakeholder groups. A collective understanding and vision necessitates a high degree of ownership and responsibility of the process, especially given the largely informal and voluntary nature of collaborative processes. Several interviewees stated that the incentives to cooperate with recalcitrant stakeholder groups are low and that they see greater value and effectiveness in finding allies with common visions, mutual understandings, and shared intrinsic responsibility. However, when decision-making processes are applied with a collective and goal-orientated approach that is transparent and informal, or at minimum cognisant of political dynamics, even stakeholders with more stringent positions have shown political manoeuvrability in formally supporting marine conservation measures.

Interdependencies and interconnectedness between marine regions were highlighted by interviewees to support the articulation of co-developed meaningful goals through the identification of commonalities. However, it should be ensured that the co-produced knowledge feeds into formal governance arrangements or processes held by other sectors. One interviewee suggested that to increase engagement with private sector stakeholders, generated outputs could for example be disseminated at platforms where the private sector is highly engaged, such as the World Economic Forum.

\section{Trust Building}

Trust building processes are an integral underlying condition and driver for successful cross-sectoral and multi-stakeholder dialogue processes in marine regions. As stated by the interviewees, physical manifestations of trust are usually documented through agreements such as memoranda of understanding, but building meaningful trust is a longterm process. It requires human and financial resources to provide continuous, long term commitment for sustainable cooperation between stakeholders. One interviewee stated that when there is a pre-history of antagonism from stakeholders and sectors, simply building trust and receiving informal commitment from such stakeholders can be the most prominent success of a collaborative effort and is sometimes the main objective of facilitation. Collaborative strategies should from the onset budget for the human, financial, and time resources required to build effective and long-term perspective and commitment, and to achieve common goals.

Ocean sustainability includes the perspective of marine conservation and protection (e.g., through marine protected areas or no-take-zones), but also of sustainable use (e.g., by fisheries or tourism). Divergent perspectives require multiple actors with diverse aims and conflicting interests to collaborate and can be viewed as collective action dilemmas (Bowen et al., 2017). Addressing collective action in marine regions requires trust, enabled by inclusive decision spaces for stakeholders to interact across multiple sectors, levels, and scales, such as through participatory approaches and tools. This can include the engagement of sectors in integrated coastal management or marine spatial planning, and although these tools are not novel, interviewees stated that not all sectors in marine regions are familiar with them and can still be a powerful facilitation tool to increase awareness of other stakeholder perspectives, build trust, and in finding compromise.

\section{Inclusivity}

Collaborative spaces should be inclusive, explicitly acknowledging the diversity of knowledge and applying this knowledge not for, but within collaborative processes. Inclusiveness, empowerment, and representation of weaker or marginalised stakeholder groups require a commitment to a positive strategy from the collaborative process. Power and resource imbalances must be recognised, not just pertaining to human resources but time and financial sustainability, as these are ultimately systemic within and across marine regions, in vertical and horizontal governance structures. Collaborative strategies should also consider power and resource imbalances in their effect on stakeholder abilities to develop long-term trust, shared understandings, and common goals. Conveners of inclusive dialogue spaces should identify and map stakeholders in the region with impartiality and involve stakeholder perspectives through culturally appropriate participatory methods to achieve their full, frequent, and active engagement, and facilitate ownership of the process. Applying these approaches from the onset of the project and allowing time for concerns to be understood and addressed have been catalytic for high-quality inclusive dialogue processes.

Given the lack of collaborative spaces and lack of understanding and preparedness of stakeholders to engage in such processes, these spaces should be made transparent and accessible. Stakeholders which are invested or affected by the decisions should have a basic understanding of what collaborative processes entail, and the implications it can have for them. Capacity development could enable this, building up the stakeholders understanding of the process and language used in collaborative processes, thereby making such processes more transparent and accessible for stakeholders.

Coherence among stakeholders can also be achieved through co-dependency - as the actions of one actor impacts actions, successes, or failures of others. However, co-dependency can also lead to increased competition for resources as stated by one interviewee, can reinforce mistrust and exclusion of stakeholder groups. It was emphasised by an interviewee that the SDGs are vastly accepted by most stakeholders in marine regions and can provide a common overarching framework for stakeholders to align interests and possibly also circumventing the otherwise high degree of technical and political efforts required to build and establish bilateral agreements, targets, and assessment criteria. However, some interviewees pointed out that the SDGs and other formal goals or processes are not tangible enough for the national level of implementation, further resulting in coordination issues and political challenges. 


\section{Interactive Continuity}

Productive collaborative processes in marine regions were characterised by interviewees as processes with high engagement and interaction (i.e., high levels of two-way engagement), and continuous (or frequent) learnings from each other with commitment to the process. This is especially important to acknowledge in marine regions with vast geographies and resource allocations (e.g., in the Pacific). Strengthening or improving the practice of interactive continuity within collaborative processes also requires sound evaluation and better monitoring of dialogue processes through pre-determined and co-developed metrics to assess their implementation. This also implores that resources should be budgeted and allocated to enable monitoring and evaluation mechanisms. The complex and iterative nature of collaborative dialogue spaces necessitates evaluation processes that can capture the complexities associated with marine regions and let conveners observe emergent successes, lessons-learned, and outcomes.

Continuity of the collaborative process can be enabled by ensuring financial sustainability, especially as this is often the limiting factor driving time constraints and ultimately longterm commitment challenges in marine regions. Meaningful engagement by funding bodies should be improved and approaches such as budget tracking (identifying where financial resources are flowing to or away and which agencies have provided what support) allows national authorities to understand financial priorities and improve capacity gaps in marine regions. It also allows the national and regional level to increase ownership and targeting of resources, which can be significant for marine regions where development and investments are funded by external states which can result in further power imbalances.

\section{Experiences of the Marine Regions Forum 2019 - A Case Study of a Cross-Sectoral Multi-Stakeholder Dialogue Platform}

In this section, the Marine Regions Forum is reflected upon to illustrate both the strengths and challenges of genuine efforts to cultivate collective action through informal dialogue across sectors and stakeholder groups. When asked about their experiences and perspectives of the Marine Regions Forum 2019 (Institute for Advanced Sustainability Studies et al., 2020; Neumann et al., 2021), the first international multi-stakeholder meeting held under this initiative, interviewees indicated that the informal networking with actors from other regions, sectors, and stakeholder groups was a core significance of attending the Forum (see Figure 1, middle lower box), especially as these types of interactions are uncommon in marine regions and would usually require financial and time resources to establish and ultimately sustain.

More specifically, interviewees stated that the Forum facilitated dialogue and engagement opportunities for stakeholders across sectors and interest groups that usually wouldn't interact, sharing of lessons learned, and identifying possible synergies between their practices. The multi-stakeholder cross-sectoral nature of the Forum provided participants with an increased sense of awareness, trust, and appreciation of common or divergent interests as well as underlining the needs of other stakeholder groups. According to the interviews, the informal nature of the Forum also led to actors from opposing sectors and interest groups to attend working groups together, encouraging openness to other topics and adapting their interests or priorities to new issues when both parties formulated respective interests. For instance, participants establishing informal, cross-sectoral dialogue (e.g., nature conservation NGOs interacting informally with a Regional Fisheries Body) and both attending alternative thematic sessions (e.g., on Deep Seabed Mining) increased the chances of generating new cross-sectoral knowledge and cooperation on themes that are currently not within the scope of the parties. This indicates a fostering of cross-sectoral, joint learning processes among the participants.

The interviewees showed that the informality of the dialogue processes at the Forum led to a number of highly practical discussions between actors from different regions and sectors on how these actors could support, partner, or cooperate each other on cross-regional and cross-sectoral topics that interested both parties. It also led to a range of other outcomes, such as the creation of new partnerships and funding. A concrete example is the grant awarded by the Western Indian Ocean Marine Science Association (WIOMSA) to the Seychelles' Conservation and Climate Adaptation Trust (SeyCCAT), for which connections were made in the follow-up of the 2019 Forum where representatives of both parties had met and SeyCCAT presented during the plenum. The grant allows SeyCCAT to develop knowledge management tools and to share its experience, lessons learned and projects to other countries of the Western Indian Ocean (WIO) region.

Interviewees also stated that at an intrinsic level, the Forum provided them with greater conviction of the regional level, increased awareness of inclusive decision spaces and how to apply their knowledge, as well as improving their own knowledge gaps on interregional processes relevant to their work. Gaining perspectives from a diversity of stakeholders further shaped current research ideas and ocean management practices toward a different school of thinking through the sharing of lessons-learned and successful or unsuccessful approaches to ocean sustainability.

Critical reflections by interviewees revealed where and how the collaborative strategy of the Forum could be further improved. Feedback indicated that the informalities contributed to encouraging interactions between participants, and although the more formal contributions from high-level speakers during plenum were recognised as important to create buy-in, participants found it drew attention and created a more formal setting. Some interviewees perceived a higher engagement with participants they were familiar with or attended working groups within their discipline rather than branching out to other thematic areas. However, it must be recognised that interactions with familiar allies and topics are also highly beneficial for already established partnerships. The value lies within deepening trust, ensuring commitments, and more 
effective communication, coordination, and cooperation through face-to-face dialogue.

\section{DISCUSSION}

The key motivation behind this study is to provide a better understanding of the challenges and opportunities of collaborative processes in and across marine regions as well as comprehend how informal, inclusive spaces for dialogue and knowledge exchange, specifically the Marine Regions Forum, can facilitate transformation toward integrated ocean governance practices. Creating inclusive dialogue spaces to enable collective action is considered a major governance challenge to successfully implementing SDGs (Bowen et al., 2017). The central findings of this paper offer insight into bridging the gap of current collaborative efforts in marine regions to strengthen regional ocean governance.

Figure 1 illustrates the overall findings of this paper on the challenges and opportunities for cross-sectoral multi-stakeholder collaborations among marine regions, and is based on the contingency theory by Ansell and Gash (2007), i.e., within the analytical framework identified from the literature (see section "Materials and Methods"). The model (Figure 1) has four broad variables as explained below, including critical common starting conditions, principles to overcoming challenges, facilitative leadership i.e., the Marine Regions Forum, as case study example for a collaborative process, and outcomes of such processes. These variables are not independent of each other, but are rather connected and influence each other. The critical common starting conditions are the entrenched or systemic challenges faced by marine regions which typically constrain but also provide reason for collaboration. At the heart of the model lie the principles to overcome such challenges. They are presented cyclically as they are interconnected, interdependent and non-linear in nature. Principles to overcoming barriers include common goal orientation, inclusivity, trust building, interactive continuity, and contextualisation. The Marine Regions Forum positions itself as a variable of facilitative leadership, i.e., cultivating essential knowledge integration by creating an inclusive and informal dialogue space for stakeholder interaction across multiple sectors and scales. These variables contribute to supporting formal, global ocean governance processes, such as the implementation of SDG 14 and other ocean related SDGs of the 2030 Agenda (see Figure 1, right box).

Although marine conservation efforts, management, and implementation of measures occur at the national or local level, regional dialogue is in a unique position to coordinate knowledge integration (Tutangata and Power, 2002; Van Tatenhove, 2011) and ultimately cultivate the process of implementing common agreed-upon global frameworks into action on the ground such as in the context of the 2030 Agenda, the Post-2020 Global Biodiversity Framework currently prepared under the Convention on Biological Diversity, or discussions addressing the ocean-climate nexus within the United Nations Framework Convention on Climate Change (UNFCCC). Regional dialogue platforms can strengthen the recognition of the need for common (regional) goals and collective harmonised action as well as coherence of indicators used to measure or monitor their progress. In this context, regional deliberations need to be cohesive and innovative, capable of providing guidance and identifying synergies and trade-offs between interlinked goals (Bowen et al., 2017). Such dialogue platforms can also be used as a tool to generate greater commitment and accountability in marine regions. Especially as many global policy processes are voluntary and no formal mechanisms or sanctions are in position to ensure the achievement of set targets (Bowen et al., 2017).

Ensuring the transformative potential of collaborative spaces, such as the Marine Regions Forum, lies within the co-creative and transdisciplinary approach of these which allows the cultivation of opportunities for joint-learning and knowledge integration as a matter of practice. Facilitating multi-stakeholder and cross-sectoral interactions leads to new exchanges, perspectives, arrangements, and cooperation that allow for working fundamentally differently at the regional level. Further, participants of collaborative spaces gain a better understanding and orientation of collaborative landscapes available and how to engage in them, especially as such efforts and practices are still uncommon. In the end, it is individual responsibility and collective accountability that will facilitate the process for knowledge integration into work practices. This paper also supports the demand to incorporate reflective processes, as performed on the Marine Regions Forum, regarding lessons learned of knowledge integration within practices, to be able to assess, learn, and improve the practices (Le Tissier and Hills, 2010; Norström et al., 2020; Schmidt et al., 2020).

Based on the interview data, the approach to regional learning adopted by the Marine Regions Forum had an acknowledgeable influence on interviewees in three interlinked areas, which potentially extend to the other attendees of the Forum. Firstly, it increased the attendee's conviction of the role of the regional level, awareness of the current lack of regional knowledge integration, and the need for policy frameworks that explicitly include regional actors. Attendees also gained an insight into regional contextualisation of global frameworks and how the regional level can facilitate processes from the national to global level, including which regional actors and processes are most relevant and how to engage with these. Secondly, attendees gained an understanding of the opportunities for multi-stakeholder integration within regional practices across sectors that complement, rather than replace, existing governance frameworks. Third, the Forum fostered a joint-learning experience for the integration of knowledge across multiple sectors and scales as a matter of practice by creating an inclusive and informal dialogue space.

Possible limitations to this paper due to the fact that coorganisers of the Marine Regions Forum conducted the study and approached interviewees should be acknowledged. For example, the interview responses could be expected to be more critical had they been conducted by a third-party. However, before and during the interview process, respondents were encouraged to reflect critically which they acknowledged and were responsive toward by providing in-depth accounts of their experiences as participants. Moreover, the purpose of the research is foremost to provide a self-reflective account of the newly established 
Forum as co-organisers and to better understand collaborative processes in and among marine regions which have so far been subject to limited assessments through self-reflexivity, although this is regarded as an integral aspect to transdisciplinary research approaches (Rosendahl et al., 2015; Schmidt et al., 2020). The paper seeks to contribute to the assessment and learnings from such collaborative processes in marine regions and allow relevant stakeholders to address the challenges and also engage in selfassessment to improve the practice.

In summary, informal collaborative dialogue spaces detached from institutional settings, such as the Marine Regions Forum, have the potential to cultivate communities for sharing of lessons learned and joint-approaches to overcoming common challenges, thereby supporting transformations toward sustainability. The Forum applies transdisciplinary learning and multistakeholder collaboration as a matter of practice and provides regional contextualisation of global frameworks in support of implementing of the 2030 Agenda. As depicted in Figure 1, the Forum is positioned within the collaborative process landscape and contributes to both informal and formal processes, consolidating discussions around regional approaches, which are usually highly contextualised, and facilitated a common understanding of interregional challenges and opportunities. It not only placed emphasis on regional cooperation but also achieved to value actors irrespective of the inherent power differences among different types of regional mechanisms or arrangements sharing the space. This further encouraged innovative thinking on how regional mechanisms can cooperate and collaborate to facilitate the implementation of global goals, which in turn reduced the usual competition between the regional actors or sectoral arrangements and placed them on equal footing to each other.

\section{CONCLUSION}

This study sets out to investigate the challenges and opportunities of current collaborative processes in marine regions and provides critical reflections of the Marine Regions Forum - a newly established inclusive dialogue and exchange platform that brings actors together across multiple stakeholder groups, sectors, and marine regions in a genuine effort to enable the transformative change for the sustainable use and conservation of marine environments. The findings have both scholarly relevance and practice-based significance by providing a better understanding of the opportunities and underlying challenges of current collaborative efforts in marine regions and possible pathways to address these. Further, it is exemplified how informal collaborative processes, such as the Marine Regions Forum, can facilitate the transformation toward sustainable oceanrelated governance practices and support global goals and targets through cultivating essential knowledge integration in marine regions by creating an inclusive dialogue spaces and opportunity for stakeholder engagement across multiple sectors and scales. To further support collaborative processes in marine regions, which are regarded as uncommon, and to advance the work of the Marine Regions Forum, the project will be taken into a second phase. Building on the outcomes of this study and lessons learned from the first Forum, the follow-up project aims to be more regionally focussed, by engaging with a specific marine region to further support transformative ocean action toward the conservation and sustainable use of marine and coastal ecosystems.

Transforming global goals and targets such as the SDGs into action on the ground, especially in light of complex socialecological issue settings such as "the ocean," requires a systemic approach to capitalise on synergies and avoid trade-offs, rather than focussing on single goals and targets (Griggs et al., 2017; Nilsson et al., 2018). The delivery of such systemic approaches is hampered by the current institutional and legal fragmentation in ocean governance, but also by other problems such as underdeveloped cultures of collaboration and coordination. Regionally coordinated approaches will be required to achieve advances in the marine environment given these challenges and the accelerating pace of ocean decline. To transcend the prevailing sectoral divides, collaborative approaches are needed that seek the delivery of joint policy development and implementation, bringing together all relevant actors for codesign and co-delivery. In the context of the ocean, the regional level is well suited to facilitate and coordinate multi-stakeholder collaborations across sectors and cultivate knowledge integration to foster the process of implementing global frameworks into action on the ground. Given the complexity of transformation processes toward ocean sustainability, collaborative stakeholder dialogues are suitable to provide the transdisciplinary and knowledge-based guidance needed for use within practices. Synergies and trade-offs amongst regional interests should be identified to ensure effective and fair outcomes such that the lessons learned are relevant and valuable to the other marine regions. By complementing existing processes, facilitating multi-stakeholder exchanges across sectors, and disseminating emerging recommendations to the formal policy processes, informal dialogue spaces for marine regions have the potential to make real progress in ocean governance and sustainability transformations.

The decisions taken and implemented now and in the next decade will be decisive for the future of the ocean. The Marine Regions Forum was set up as an inclusive dialogue space for joint-learning and to support current collaborative efforts within and across marine regions, and by that strengthen regional ocean governance. It has demonstrated that such regional stakeholder processes have the potential to foster facilitative leadership and encourage multi-stakeholder knowledge integration across sectors. Collaborative efforts contribute to supporting formal ocean governance processes at the regional and global level, such as the implementation of SDG 14 and other ocean related SDG's that aim to achieve sustainable use and conservation of the ocean and its resources while delivering a more sustainable future for all.

\section{DATA AVAILABILITY STATEMENT}

The raw data supporting the conclusions of this article will be made available by the authors, without undue reservation. 


\section{ETHICS STATEMENT}

Ethical review and approval was not required for the study on human participants in accordance with the local legislation and institutional requirements. The patients/participants provided their written informed consent to participate in this study.

\section{AUTHOR CONTRIBUTIONS}

LW, BN, and SU contributed to the conception or design of the work and jointly conceptualised the manuscript. LW organised and conducted the collection and analysis of the interview data for this work and wrote the first draft. BN and SU contributed to sections of the manuscript and revised it critically together with LW, JR, and AM. All authors contributed to manuscript revision, read, and approved the submitted version.

\section{FUNDING}

Funding for this research was provided to LW, JR, and AM by the German Environment Agency through the departmental research plan (Ressortforschungsplan) of the German Federal Ministry for the Environment, Nature Conservation and Nuclear

\section{REFERENCES}

Ansell, C., and Gash, A. (2007). Collaborative governance in theory and practice. J. Public Administr. Res. Theor. 18, 543-571. doi: 10.1093/jopart/mum032

Berkowitz, H., Crowder, L. B., and Brooks, C. M. (2020). Organizational perspectives on sustainable ocean governance: A multi-stakeholder, metaorganization model of collective action. Mar. Policy 118:104026. doi: 10.1016/j. marpol.2020.104026

Billé, R., Chabason, L., Drankier, P., Molenaar, E. J., and Rochette, J. (2017). "Regional oceans governance: making Regional Seas programmes, regional fishery bodies and large marine ecosystem mechanisms work better together," in Handbook on the Economics and Management of Sustainable Oceans. Cheltenham, UK: Edward Elgar Publishing. doi: 10.4337/9781786430724.00036

Booher, D. E. (2004). Collaborative governance practices and democracy. Natl. Civic Rev. 93, 32-46. doi: 10.1002/ncr.69

Bowen, K. J., Cradock-Henry, N. A., Koch, F., Patterson, J., Häyhä, T., Vogt, J., et al. (2017). Implementing the "Sustainable Development Goals": towards addressing three key governance challenges-collective action, trade-offs, and accountability. Curr. Opin. Env. Sustain. 2017, 90-96. doi: 10.1016/j.cosust. 2017.05.002

Bremer, S., and Meisch, S. (2017). Co-production in climate change research: reviewing different perspectives. Wiley Interdiscip. Rev.: Climate Change 8:e482. doi: $10.1002 /$ wcc.482

Chung, S. Y. (2010). Strengthening regional governance to protect the marine environment in Northeast Asia: From a fragmented to an integrated approach. Mar. Policy 34, 549-556. doi: 10.1016/j.marpol.2009. 10.011

Cvitanovic, C., Hobday, A. J., Van Kerkhoff, L., and Marshall, N. A. (2014). Overcoming barriers to knowledge exchange for adaptive resource management; the perspectives of Australian marine scientists. Mar. Policy 52, 38-44. doi: 10.1016/j.marpol.2014.10.026

Cvitanovic, C., Hobday, A. J., van Kerkhoff, L., Wilson, S. K., Dobbs, K., and Marshall, N. A. (2015). Improving knowledge exchange among scientists and decision-makers to facilitate the adaptive governance of marine resources: A review of knowledge and research needs. Ocean Coastal Manag. 112, 25-35. doi: 10.1016/j.ocecoaman.2015.05.002
Safety via project FKZ $371725261 \quad 0$. The work of BN and SU was supported by the German Federal Ministry of Education and Research (BMBF) through its Research for Sustainable Development program (FONA), and the Federal State of Brandenburg.

\section{ACKNOWLEDGMENTS}

We would like to express our sincere thanks to the participants of this study for their input and interest in the study, to our donors for their support of this research, and to all colleagues who contributed to the conceptualisation and implementation of this study, foremost to Giulia Molinengo, Daniel Oppold, and Dorota Stasiak from the Institute for Advanced Sustainability Studies for their input on the analytical framework. We would like to express our sincere gratitude to the interview participants for taking part in the research and providing their valuable input.

\section{SUPPLEMENTARY MATERIAL}

The Supplementary Material for this article can be found online at: https://www.frontiersin.org/articles/10.3389/fmars. 2021.645576/full\#supplementary-material

Dale, A., and Armitage, D. (2011). Marine mammal co-management in Canada's Arctic: Knowledge co-production for learning and adaptive capacity. Mar. Policy 35, 440-449. doi: 10.1016/j.marpol.2010. 10.019

DeCuir-Gunby, J. T., Marshall, P. L., and McCulloch, A. W. (2011). Developing and using a codebook for the analysis of interview data: An example from a professional development research project. Field Methods 23, 136-155. doi: $10.1177 / 1525822 \times 10388468$

Fereday, J., and Eimear, M.-C. (2006). Demonstrating Rigor Using Thematic Analysis: A Hybrid Approach of Inductive and Deductive Coding and Theme Development. Int. J. Q. Methods 5, 80-92. doi: 10.1177/160940690600500107

Gopnik, M., Fieseler, C., Cantral, L., McClellan, K., Pendleton, L., and Crowder, L. (2012). Coming to the table: Early stakeholder engagement in marine spatial planning. Mar. Policy 36, 1139-1149. doi: 10.1016/j.marpol.2012.02.012

Griggs, D. J., Nilsson, M., Stevance, A.-S., and McCollum, D. (2017). A Guide to SDG Interactions: from Science to Implementation. Paris: International Council for Science

Guest, G., Bunce, A., and Johnson, L. (2006). How Many Interviews Are Enough?: An Experiment with Data Saturation and Variability. Field Methods 18, 59-82. doi: 10.1177/1525822X05279903

Hay, I. (2010). Qualitative Research Methods in Human Geography, 3rd Edn. Oxford: Oxford University Press.

Heinrich Böll Foundation (2017). Ocean Atlas. In Ocean Atlas - Facts and Figures on the Threats to our Marine Ecosystems. Available online at: https://www.boell. de/sites/default/files/web_170607_ocean_atlas_vektor_us_v102.pdf (accessed date, May 2017)

Institute for Advanced Sustainability Studies, Institute for Sustainable Development and International Relations, and Tmg - ThinkTank for Sustainability. (2020). Marine Regions Forum 2019: Achieving a healthy ocean - regional ocean governance beyond 2020 Conference Report. Germany: Institute for Advanced Sustainability Studies (IASS); Institute for Sustainable Development and International Relations (IDDRI); TMG - ThinkTank for Sustainability (TMG). doi: 10.2312/ iass.2020.001

Le Tissier, M. D. A. A., and Hills, J. M. (2010). Practitioner training for building capacity in ICZM. Ocean Coastal Manag. 53, 787-795. doi: 10.1016/ j.ocecoaman.2010.10.018 
Mahon, R., and Fanning, L. (2019). Regional ocean governance: Polycentric arrangements and their role in global ocean governance. Mar. Policy 107:103590. doi: 10.1016/j.marpol.2019.10 3590

Mauser, W., Klepper, G., Rice, M., Schmalzbauer, B. S., Hackmann, H., Leemans, R., et al. (2013). Transdisciplinary global change research: The co-creation of knowledge for sustainability. Curr. Opin. Env. Sustainabil. 5, 420-431. doi: 10.1016/j.cosust.2013.07.001

Mazor, T., Possingham, H. P., and Kark, S. (2013). Collaboration among countries in marine conservation can achieve substantial efficiencies. Div. Distrib. 19, 1380-1393. doi: 10.1111/ddi.12095

Morgan, J. R. (1991). Marine regions and the Law of the Sea. Ocean Shorel. Manag. 15, 261-271. doi: 10.1016/0951-8312(91)90019-X

Neumann, B., Unger, S., Weiand, L., Rochette, J., Wright, G., and Müller, A. (2021). Final Report - Marine Regions Forum: An international stakeholder forum to strengthen regional ocean governance. (in press) Germany: German Environment Agency.

Nilsson, M., Chisholm, E., Griggs, D., Howden-Chapman, P., McCollum, D., Messerli, P., et al. (2018). Mapping interactions between the sustainable development goals: lessons learned and ways forward. Sustainabil. Sci. 13, 0604-z. doi: 10.1007/s11625-018-0604-z

Norström, A. V., Cvitanovic, C., Löf, M. F., West, S., Wyborn, C., Balvanera, P., et al. (2020). Principles for knowledge co-production in sustainability research. Nat. Sustainabil. 9, 448-442. doi: 10.1038/s41893-0190448-2

Ritchie, H., and Ellis, G. (2010). 'A system that works for the sea'? Exploring Stakeholder Engagement in Marine Spatial Planning. J. Env. Plan. Manag. 53, 701-723. doi: 10.1080/09640568.2010.488100

Ritchie, J., and Lewis, J. (2003). Qualitative Research Pratice: A Guide for Social Science Students and Researchers. Thousand Oaks: SAGE Publications Ltd.

Rochette, J., Billé, R., Molenaar, E. J., Drankier, P., and Chabason, L. (2015). Regional oceans governance mechanisms: A review. Mar. Policy 60, 9-19. doi: 10.1016/j.marpol.2015.05.012

Rosendahl, J., Zanella, M. A., Rist, S., and Weigelt, J. (2015). Scientists' situated knowledge: Strong objectivity in transdisciplinarity. Futures 65, 17-27. doi: 10.1016/j.futures.2014.10.011

Schmidt, L., Falk, T., and Siegmund-schultze, M. (2020). The Objectives of Stakeholder Involvement in Transdisciplinary Research. A Conceptual Framework for a Reflective and Reflexive Practise. Ecol. Econom. 176:106751. doi: 10.1016/J.ECOLECON.2020.106751

Schmidt, S., Neumann, B., Waweru, Y., Durussel, C., Unger, S., and Visbeck, M. (2017). "SDG14 Conserve and sustainably use the oceans, seas and marine resources for sustainable development," in A Guide to SDG Interactions: from Science to Implementation, eds D. J. Griggs, M. Nilsson, A.-S. Stevance, and D. McCollum (Paris: International Council for Science), 174-218.
Spalding, M. D., Fox, H. E., Allen, G. R., Davidson, N., Ferdaña, Z. A., Finlayson, M., et al. (2007). Marine Ecoregions of the World: A Bioregionalization of Coastaland Shelf Areas. BioScience 57, 573-583.

Stafford-Smith, M., Griggs, D., Gaffney, O., Ullah, F., Reyers, B., Kanie, N., et al. (2017). Integration: the key to implementing the Sustainable Development Goals. Sustain. Sci. 12, 911-919. doi: 10.1007/s11625-016-0383-3

Tutangata, T., and Power, M. (2002). The regional scale of ocean governance regional cooperation in the Pacific Islands. Ocean Coastal Manag. 45, 873-884. doi: 10.1016/S0964-5691(02)00111-4

United Nations (2015). Transforming our world: the 2030 Agenda for Sustainable Development. UNGA Resolution A/RES/70/1. Resolution adopted by the General Assembly on 25 September 2015 70/1. General Assembly. New York, NY: United Nations General Assembly.

United Nations (2017). The Ocean Conference - Partnership for Regional Ocean Governance: International Forum for Advancing Regional Ocean Governance. New York, NY: United Nations.

Van Tatenhove, J. (2011). Integrated marine governance: Questions of Legitimacy. MAST. 10. 87-113.

Voorberg, W. H., Bekkers, V. J. J. M., and Tummers, L. G. (2015). A systematic review of co-creation and co-production: Embarking on the social innovation journey. Public Manag. Rev. 17, 1333-1357.

Watson-Wright, W., and Luis Valdés, J. (2019). Fragmented Governance of Our One Global Ocean. In The Future of Ocean Governance and Capacity Development. Leiden: Brill | Nijhoff. 16-22. doi: 10.1163/9789004380271_005

West, S., van Kerkhoff, L., and Wagenaar, H. (2019). Beyond "linking knowledge and action": towards a practice-based approach to transdisciplinary sustainability interventions. Policy Stud. 40, 534-555. doi: 10.1080/01442872. 2019.1618810

Wright, G., Schmidt, S., Rochette, J., Shackeroff, J., Unger, S., Waweru, Y., et al. (2017). Partnering for a sustainable ocean: The Role of Regional Ocean Governance in Implementing Sustainable Development Goal 14. Partnership for Regional Ocean Governance (PROG). Potsdam: Institute for Advanced Sustainability Studies (IASS). doi: 10.2312/iass.2017.011

Conflict of Interest: The authors declare that the research was conducted in the absence of any commercial or financial relationships that could be construed as a potential conflict of interest.

Copyright (c) 2021 Weiand, Unger, Rochette, Müller and Neumann. This is an openaccess article distributed under the terms of the Creative Commons Attribution License (CC BY). The use, distribution or reproduction in other forums is permitted, provided the original author(s) and the copyright owner(s) are credited and that the original publication in this journal is cited, in accordance with accepted academic practice. No use, distribution or reproduction is permitted which does not comply with these terms. 